\section{ACCURACY AND PRECISION OF A NEW, PORTABLE, HANDHELD BLOOD GAS ANALYZER, THE IRMA ${ }^{\circledR}$}

Joyce A. Wahr, MD, Wei Lau, MD, Kevin K. Tremper, $M D$, PhD, Lucy Hallock, RN, MS, and Kaye Smith, RN
From the Department of Anesthesiology, University of Michigan Medical School, Ann Arbor, Michigan.

Received Oct 4, 1995, and in revised form Mar 6, 1996. Accepted for publication Mar 11, 1996.

Address correspondence to Dr. Wahr, Department of Anesthesiology, University of Michigan Hospitals, 1G323-0048, 1500 E. Medical Center Drive, Ann Arbor, MI 48109-0048, U.S.A.
Wahr JA, Lau W, Tremper KK, Hallock L, Smith K. Accuracy and precision of a new, portable, handheld blood gas analyzer, the IRMA $^{\circledR}$

J Clin Monit 1996; 12: 317-324

ABSTRACT. Objective. The accuracy and precision of the new IRMA $^{\circledR}$ (Immediate Response Mobile Analysis System, Diametrics, Inc. ${ }^{\mathbb{B}}$, St. Paul, MN) handheld blood gas analyzer was compared with that of two benchtop blood gas analyzers. The IRMA consists of a notebook-sized machine and disposable cartridges, each containing a $\mathrm{pH}, \mathrm{a} \mathrm{CO}_{2}$ and an $\mathrm{O}_{2}$ electrode, and provides bedside (point-of-care) blood gas analysis. Methods. A total of 172 samples (arterial and mixed venous) were obtained from 25 informed, consenting patients undergoing cardiopulmonary bypass. The $\mathrm{pH}, \mathrm{PCO}_{2}$ and $\mathrm{PO}_{2}$ of each sample was determined on four blood gas analyzers: NOVA Statlabs Profile 5 (NOVA Biomedical, Waltham, MA), the ABL-50 (Radiometer, West Lake, OH), and two IRMA machines. Linear regression and bias \pm precision were determined, comparing each of the analyzers with the NOVA. Results. All three machines showed a similar, high degree of correlation with the NOVA for $\mathrm{pH}, \mathrm{PCO}_{2}$, and $\mathrm{PO}_{2}$. The bias and precision of the IRMA machines compared with the NOVA was similar to that of the ABL compared with the NOVA for $\mathrm{pH}$ (NOVA:ABL $-0.005 \pm 0.011$; NOVA : IRMA $1=0.0026 \pm 0.025 ;$ NOVA : IRMA $2=0.0021 \pm 0.025)$, for $\mathrm{PCO}_{2}$ (NOVA:ABL $=-1.4 \pm 1.3 \mathrm{mmHg}$; NOVA : IRMA 1 $=-1.3 \pm 1.9 \mathrm{mmHg}$; NOVA : IRMA $2=-1.2 \pm 2.1 \mathrm{mmHg}$ ) and $\mathrm{PO}_{2}$ (NOVA:ABL $=3.6 \pm 21.1 \mathrm{mmHg}$; NOVA : IRMA 1 $=3.4 \pm 19.9 \mathrm{mmHg}$; NOVA : IRMA $2=6.3 \pm 20.9 \mathrm{mmHg}$ ). The bias found for $\mathrm{pH}, \mathrm{PCO}_{2}$, and $\mathrm{PO}_{2}$ was not affected by extremes of temperature (range $25.5-40^{\circ} \mathrm{C}$ ) or hematocrit (range 11-44\%) for any machine. Conclusions. The new technology incorporated in the IRMA blood gas analyzer provides results with an accuracy that is similar to that of benchtop analyzers, but with all of the advantages of point-ofcare analysis.

KEY WORDS. Blood gas analyses. Monitoring: oxygen, carbondioxide, pH. Equipment: point of care blood gas analyzer.

\section{INTRODUCTION}

In critically ill or anesthetized patients, the ability to quantitatively assess blood gas status is invaluable. Development of the polarographic oxygen electrode in 1956 by Leland Clark, and of the Severinghaus $\mathrm{CO}_{2}$ electrode shortly thereafter, made clinical monitoring of blood gases a routine part of patient care. Despite improvements in the speed with which current benchtop analyzers can perform an analysis, they are not portable, requiring transport of blood samples to the laboratory. Delays in transport or mishandling of the samples (e.g., allowing air bubbles to come in contact with the blood, too much or too little heparin in the sample, lost labels, warming of the sample) can significantly affect the accu- 
racy of the results or delay appropriate intervention in patient management [1-4]. The ability to bring the blood gas analyzer to the critically ill patient and to perform analysis at the bedside ("point-of-care") would alleviate many of these problems. Development of portable blood gas analyzers has been limited by the requirements for calibration of the $\mathrm{CO}_{2}$ electrode. Benchtop analyzers use known concentrations of gas, which is supplied in conventional gas tanks that severely limit their portability.

The new IRMA ${ }^{\circledR}$ (Diametrics, Inc. ${ }^{\circledR}$, St. Paul, MN) handheld blood gas analyzer consists of a battery-powered machine (approximately $12^{\prime \prime}$ by $15^{\prime \prime}$, the size of a notebook) and disposable cartridges, approximately $2^{\prime \prime}$ by $5^{\prime \prime}$ in size. The cartridges, containing a $\mathrm{pH}$ electrode, a $\mathrm{CO}_{2}$ electrode, and a polarographic $\mathrm{O}_{2}$ electrode, are supplied in a foil wrapper with a packet of bicarbonate in a gas permeable membrane. When the foil wrapper is sealed, the bicarbonate equilibrates with $\mathrm{CO}_{2}$ partial pressure. When the cartridge is removed, the gas surrounding the $\mathrm{CO}_{2}$ and $\mathrm{pH}$ electrodes is the known partial pressure of $\mathrm{CO}_{2}$, and the electrode is calibrated on insertion of the cartridge. The incorporation of the calibrating gas in the foil wrapper decreases the size of the machine to one that can be easily hand-carried. While this new technology has been tested and found to be accurate in laboratory settings, no large-scale clinical trials have been reported. We therefore studied the accuracy of this new blood gas analysis technology over a wide physiological range of temperatures, oxygen and $\mathrm{CO}_{2}$ tensions, and hematocrits in patients undergoing cardiac surgery.

\section{MATERIAL AND METHODS}

With the approval of our institutional review board, 25 patients undergoing elective cardiac surgery who gave informed consent were enrolled in this prospective study. All patients underwent placement of arterial and pulmonary artery catheters. General anesthesia was induced and maintained with fentanyl and midazolam infusions. All patients underwent systemic heparinization with 3-4 $\mathrm{mg}$ of bovine heparin. Moderate hypothermic cardiopulmonary bypass was employed in all patients (systemic cooling to a core temperature of not lower than $28^{\circ} \mathrm{C}$ ). Arterial and mixed venous blood samples were drawn following skin incision, after systemic cooling during cardiopulmonary bypass, and following successful separation from cardiopulmonary bypass. Six $3-\mathrm{ml}$ samples (three arterial and three mixed venous) were collected from each patient into pre-heparinized syringes (Smooth$E^{\circledR}$, Radiometer, West Lake, $\mathrm{OH}$ ). Each sample was analyzed in randomized order in the four blood gas analyzers: the NOVA Statlabs Profile 5 (NOVA Biomedical, Waltham, MA); the ABL-50 (Radiometer, West Lake, $\mathrm{OH}$ ); and the two IRMA machines. The order of analysis for each separate syringe was determined by a random number generator, so that order of analysis did not influence the results. All samples were analyzed within 5 minutes at room temperature and without cooling. Quality control measurements were performed daily on all analyzers using standardized control solutions (acidosis, alkalosis, and normal) in accordance with the College of American Pathologists' standards for accreditation.

Data were analyzed using the statistical program Statview 4.02 (Abacus Concepts, Berkeley, CA). Statistical analysis included linear regression and bias \pm precision as recommended by Bland and Altman [5]. Bias is the mean difference of the values and represents the systematic error between two methods, while precision is the standard deviation of the bias and represents the random error. In all cases, the NOVA-6 was considered the "gold standard," and the other machines were compared with it. The bias \pm precision between the NOVA and each of the IRMA analyzers was compared with the bias \pm precision between the NOVA and the $\mathrm{ABL}$ for all variables $\left(\mathrm{pH}, \mathrm{PCO}_{2}, \mathrm{PO}_{2}\right)$. Likewise, the correlation between the NOVA and each IRMA analyzer was compared with the correlation between the NOVA and the $\mathrm{ABL}$ analyzers using Fisher's $\mathrm{z}$ statistic. This statistic was modified to account for the inherent agreement resulting from the repetition of the NOVA value in each computation.

The effect of temperature and hematocrit on the bias of any machine was determined. The bias of each variable for each analyzer compared with the NOVA was plotted against the hematocrit (or temperature) value of that sample. The correlation between the bias and the hematocrit (or temperature) was determined. The effect of hematocrit (or temperature) on the bias of the IRMA analyzer for each variable was compared with the effect on the bias demonstrated by the ABL using the Fisher's $\mathrm{z}$ statistic, again modified to account for the inherent agreement between samples due to the repetition of the NOVA value and the hematocrit (or temperature) in each correlation.

\section{RESULTS}

The $\mathrm{pH}, \mathrm{PCO}_{2}$, and $\mathrm{PO}_{2}$ of 172 samples were determined on each of four blood gas analyzers. Results were dropped from analysis when the blood gas analyzer failed to calibrate (twice with the IRMA machines) or 
displayed an error message (four times with the NOVA and $A B L$ ). Therefore, the number of samples analyzed on each machine are different, and are detailed in the figures.

All three machines showed a high degree of correlation with the NOVA for $\mathrm{pH}$ (ABL $r=0.97$, IRMA $1 r=$ 0.89 , IRMA $2 r=0.87$ ), for $\mathrm{PCO}_{2}$ (ABL $r=0.92$, IRMA $1 r=0.95$, IRMA $2 r=0.91)$, and for $\mathrm{PO}_{2}(\mathrm{ABL} r=0.99$, IRMA $1 r=0.99$, IRMA $2 r=0.99$ ).

The bias \pm precision for each analyzer compared with the NOVA across the $\mathrm{pH}$ ranges from 7.00 to 7.60 , as shown in Figure 1. While the bias of the IRMA analyzers is similar to that of the ABL, the standard deviation appears larger for the IRMA instruments (NOVA:ABL $-0.005 \pm 0.011 ;$ NOVA : IRMA $1=0.0026 \pm 0.025$; NOVA : IRMA $2=0.0021 \pm 0.025$ ). The limits of agreement for the IRMA analyzers range from -0.04 to +0.044 . This precision appears to be sufficient for appropriate clinical decision making.

The $\mathrm{PCO}_{2}$ analysis is shown in Figure 2 . The bias and precision of each analyzer compared with the NOVA were similar across the range of values from 30 to 58 $\mathrm{mmHg}$ (NOVA: $\mathrm{ABL}=-1.38 \pm 1.33 \mathrm{mmHg}$; NOVA: IRMA $1=-1.26 \pm 1.87 \mathrm{mmHg}$; NOVA : IRMA $2=-1.16 \pm 2.08 \mathrm{mmHg}$ ). The range covered by the limits of agreement for the IRMA machines compared with the NOVA is larger than the range comparing the ABL with the NOVA $(5.6 \mathrm{mmHg}$ for ABL, $7.2 \mathrm{mmHg}$ for IRMA 1, and $8 \mathrm{mmHg}$ for IRMA 2). However, this variability is unlikely to be clinically significant; $3.5 \%$ of the samples tested were outside of the limits of agreement for $\mathrm{PCO}_{2}$ with the IRMA machines, compared with $2.4 \%$ of the values obtained with the ABL. Neither temperature or hematocrit was found to affect the bias of either IRMA analyzer when compared with the effect of temperature or hematocrit on the bias of the ABL.

The $\mathrm{PO}_{2}$ analysis, as shown in Figures 3 and 4, again demonstrates a small bias and excellent precision for each machine compared with the NOVA. Figure 3 shows the bias and precision for $\mathrm{PO}_{2}$ values less than $100 \mathrm{mmHg}$ and Figure 4 shows the bias and precision for values greater than $100 \mathrm{mmHg}$. No differences were seen in the measure of agreement with the NOVA either for the complete range of oxygen tensions (NOVA:ABL $=3.6$ $\pm 21.1 \mathrm{mmHg}$; NOVA : IRMA $1=3.4 \pm 19.9 \mathrm{mmHg}$; NOVA:IRMA $2=6.3 \pm 20.9 \mathrm{mmHg}$ ) or for values greater than $100 \mathrm{mmHg}$ (NOVA:ABL $=7.42 \pm 29.01$ mmHg; NOVA : IRMA $1=2.11 \pm 27.71 \mathrm{mmHg}$; NOVA:IRMA $2=7.63 \pm 29.14 \mathrm{mmHg}$ ). The ABL was found to have a clinically insignificant bias for $\mathrm{PO}_{2}$ values less than $100 \mathrm{mmHg}$, while the two IRMA analyzers showed a bias of approximately $5 \mathrm{mmHg}$ (NOVA:ABL $=-0.3 \pm 3.9 \mathrm{mmHg}$; NOVA : IRMA $1=$
$4.8 \pm 3.4 \mathrm{mmHg}$ : NOVA : IRMA $2=4.9 \pm 3.8 \mathrm{mmHg}$ ). The precision for each analyzer appeared to be similar for all $\mathrm{PO}_{2}$ values, and for $\mathrm{PO}_{2}$ values greater than and less than $100 \mathrm{mmHg}$.

All machines demonstrated a greater variability for $\mathrm{PO}_{2}$ values greater than 100 versus less than $100 \mathrm{mmHg}$. For $\mathrm{PO}_{2}$ values less than $100 \mathrm{mmHg}$, the range covered by the limits of agreement were similar for all machines ( $7.8 \mathrm{mmHg}$ for ABL, $6.8 \mathrm{mmHg}$ for IRMA 1, and 7.6 $\mathrm{mmHg}$ for IRMA 2). The percentage of values outside of the limits of agreement was less than $5 \%$ for all machines $(2.4 \%$ for ABL, $4.7 \%$ for IRMA $1,4.7 \%$ for IRMA 2). The bias found for $\mathrm{pH}, \mathrm{PCO}_{2}$, and $\mathrm{PO}_{2}$ was not affected by extremes of temperature (range 25.5 to $40{ }^{\circ} \mathrm{C}$ ) or hematocrit (range 11 to $44 \%$ ).

\section{DISCUSSION}

These data demonstrate that the new technology incorporated into the IRMA blood gas analyzer provides blood gas results with an accuracy and precision similar to that of traditional blood gas analyzers. There is an irreducible degree of variability in blood gas analysis. Analysis of the same blood sample repeated on the same machine repeatedly will produce results that are not identical. Therefore, this study was not concerned with the absolute agreement between a "new" instrument (IRMA) and a "gold standard" instrument (NOVA). Rather, it was concerned with whether the agreement between the "new" and the "gold standard" is different than the agreement between two "gold standard" instruments (NOVA and $\mathrm{ABL}$ ). As both the $\mathrm{ABL}$ and the NOVA analyzers are accepted as accurate and reliable individually, the degree of agreement (or disagreement) between these two instruments must be considered acceptable in clinical decision making.

This study did demonstrate some differences in bias between the NOVA-ABL and the NOVA-IRMA, most notably in $\mathrm{PO}_{2}$ values less than $100 \mathrm{mmHg}$. Because bias, or mean offset, is a systematic error, it can be corrected for in software algorithms, and the IRMA company has developed software that enables the IRMA to "emulate" any of the standard benchtop analyzers. Precision is a measure of random error, and cannot be accounted for with algorithms. The precision of each of the IRMA analyzers for $\mathrm{PCO}_{2}$ and $\mathrm{PO}_{2}$ compared with the NOVA analyzer, was similar to the precision of the $\mathrm{ABL}$ compared with the NOVA. The bias \pm precision of the IRMA analyzers for $\mathrm{pH}$ measurements also appears different from that of the ABL, when each is compared with the NOVA. The limits of agreement, however, defined as two standard deviations above and below the 

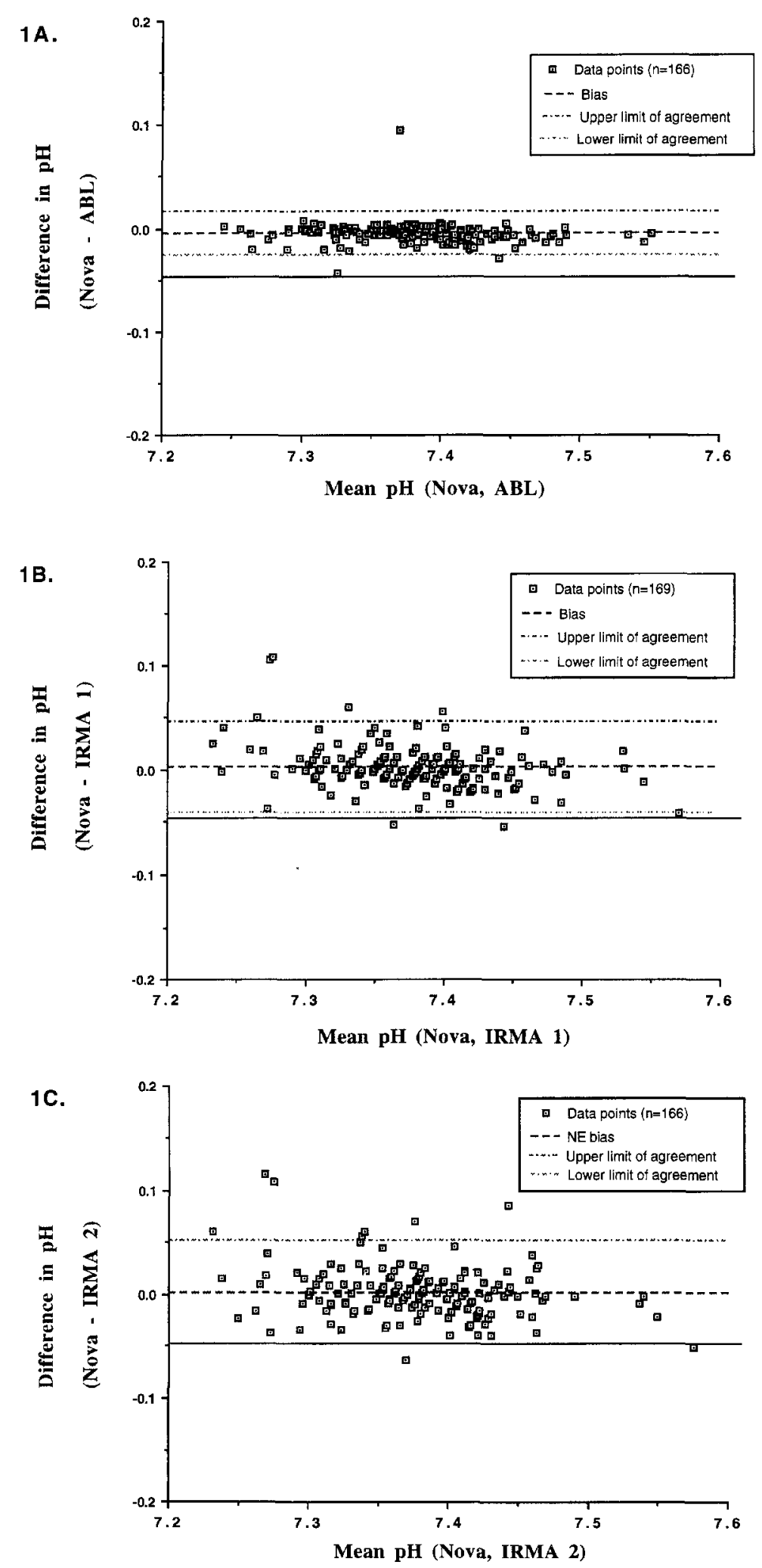

Fig 1. Bias plot of the difference in pH measurement between two analyzers and the average of the two measurement. A. Bias plot of NOVA-and $A B L$-determined $p H$ values; mean difference $=-0.005 \pm 0.011 . B$. Bias plot of NOVA-and IRMA 1 -determined $p H$ values; mean difference $=$ $0.0026 \pm 0.025$. C. Bias plot of NOVA- and IRMA 2-determined $p H$ values; mean difference $=0.0021 \pm 0.025$. 


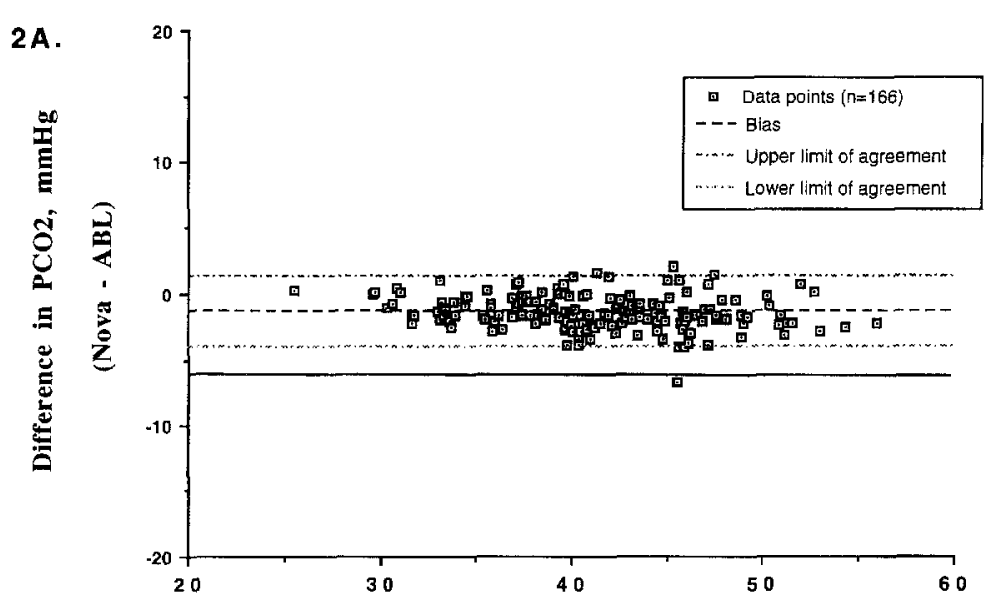

Mean PCO2, mmHg (Nova, ABL)
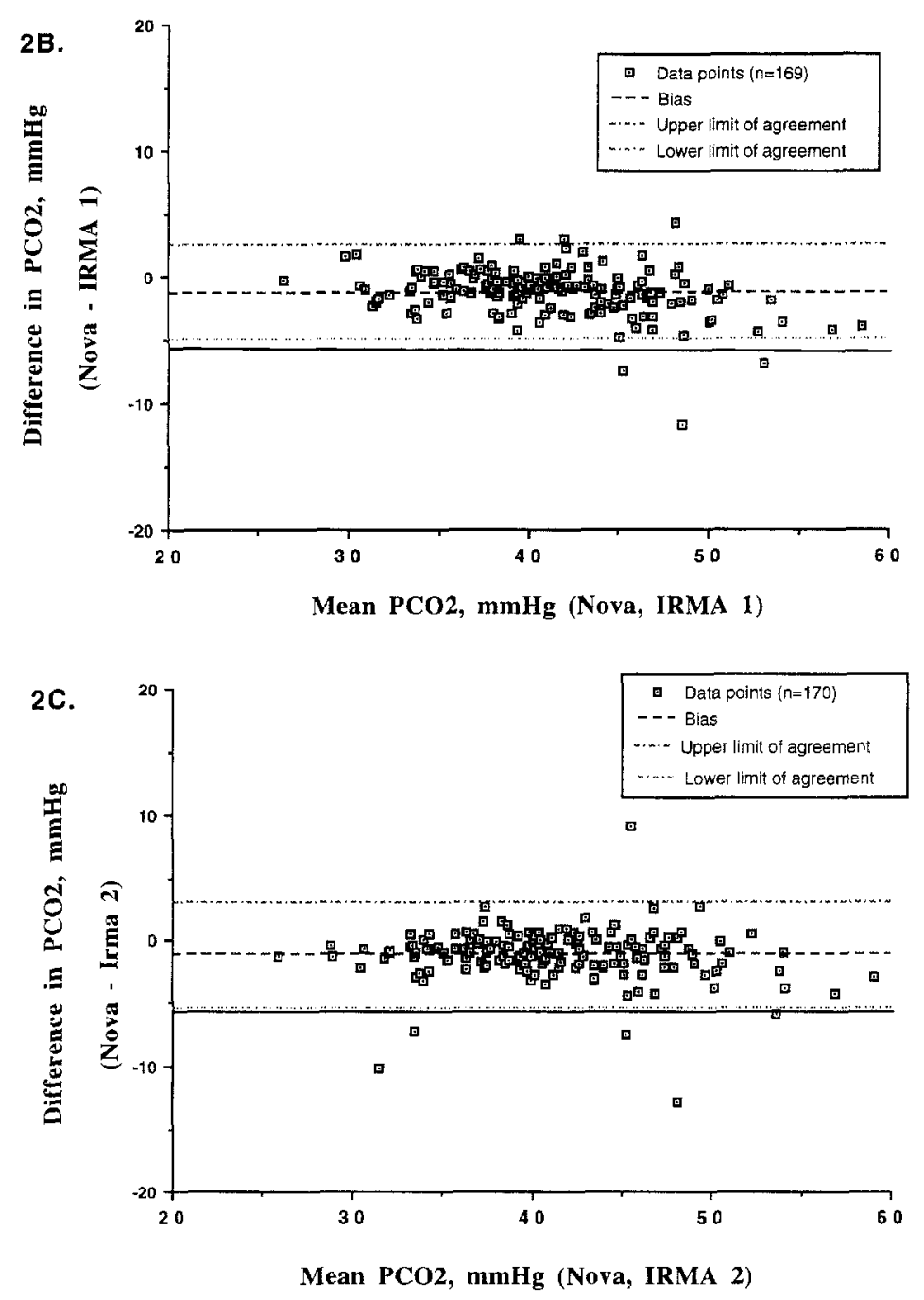

Fig 2. Bias plot of the difference in $\mathrm{PCO}_{2}$ measurement between two analyzers and the average of the two measurements. A. Bias plot of $N O V A-$ and $A B L$-determined $\mathrm{PCO}_{2}$ values; mean difference $=-1.4 \pm 1.3 \mathrm{mmHg}$. B. Bias plot of NOVA-and IRMA 1-determined $P C \mathrm{O}_{2}$ values; mean difference $=-1.3 \pm 1.9 \mathrm{mmHg}$. C. Bias plot of NOVA- and IRMA2-determined $P \mathrm{CO}_{2}$ values; mean difference $=-1.2 \pm 2.1 \mathrm{~mm} \mathrm{Hg}$. 

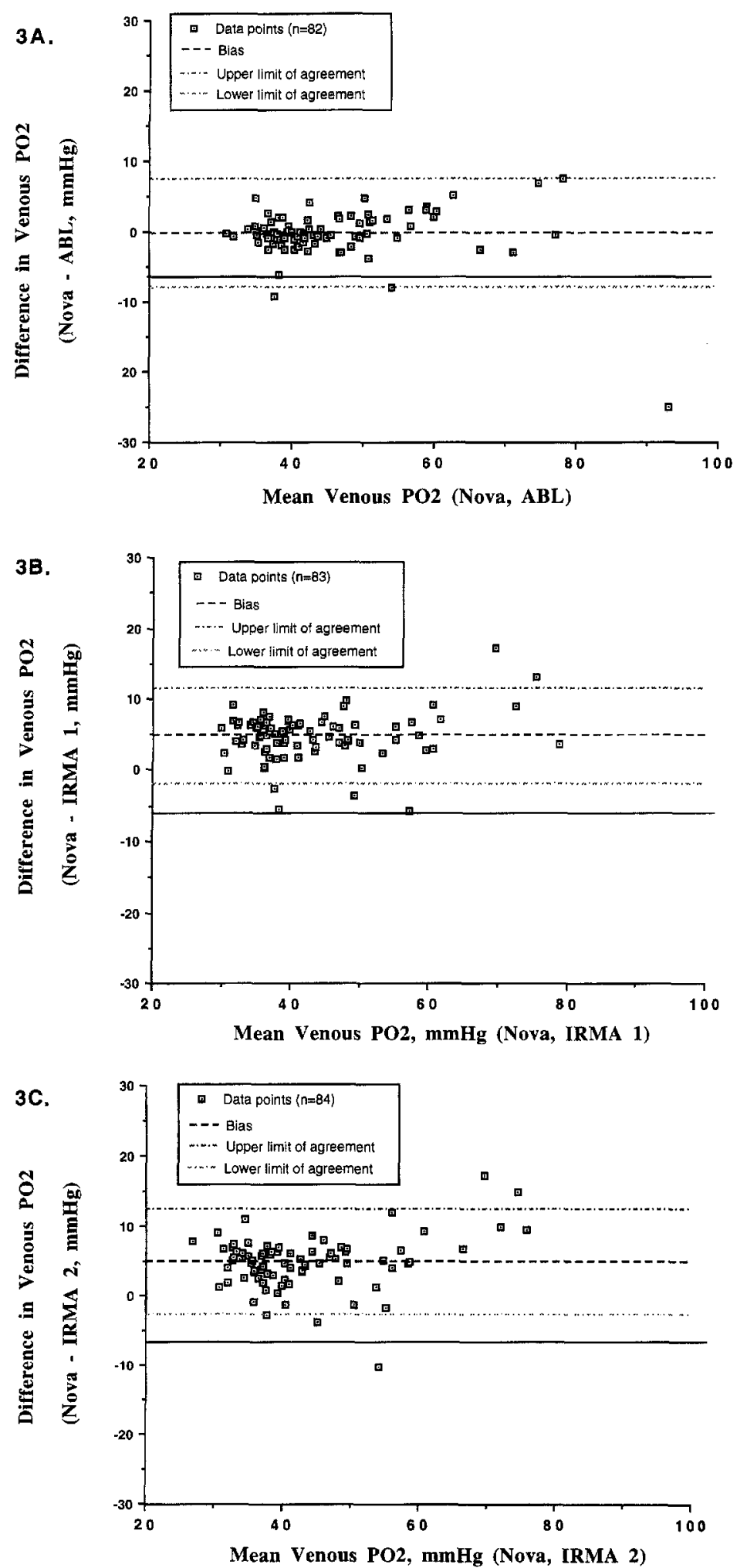

Fig 3. Bias plot of the difference in $\mathrm{PO}_{2}$ measurement between two analyzers and the average of the two measurements for $P \mathrm{O}_{2}$ values less than $100 \mathrm{mmHg}$. A. Bias plot of NOVA- and ABL-determined $\mathrm{PO}_{2}$ values; mean difference $=-0.29 \pm 3.9 \mathrm{mmHg}$. B. Bias plot of NOVA- and IRMA 1-determined $\mathrm{PO}_{2}$ values; mean difference $=4.8 \pm 3.4 \mathrm{mmHg}$. C. Bias plot of NOVA- and IRMA 2-determined $P \mathrm{O}_{2}$ values; mean difference $=4.9 \pm 3.8 \mathrm{mmHg}$. 

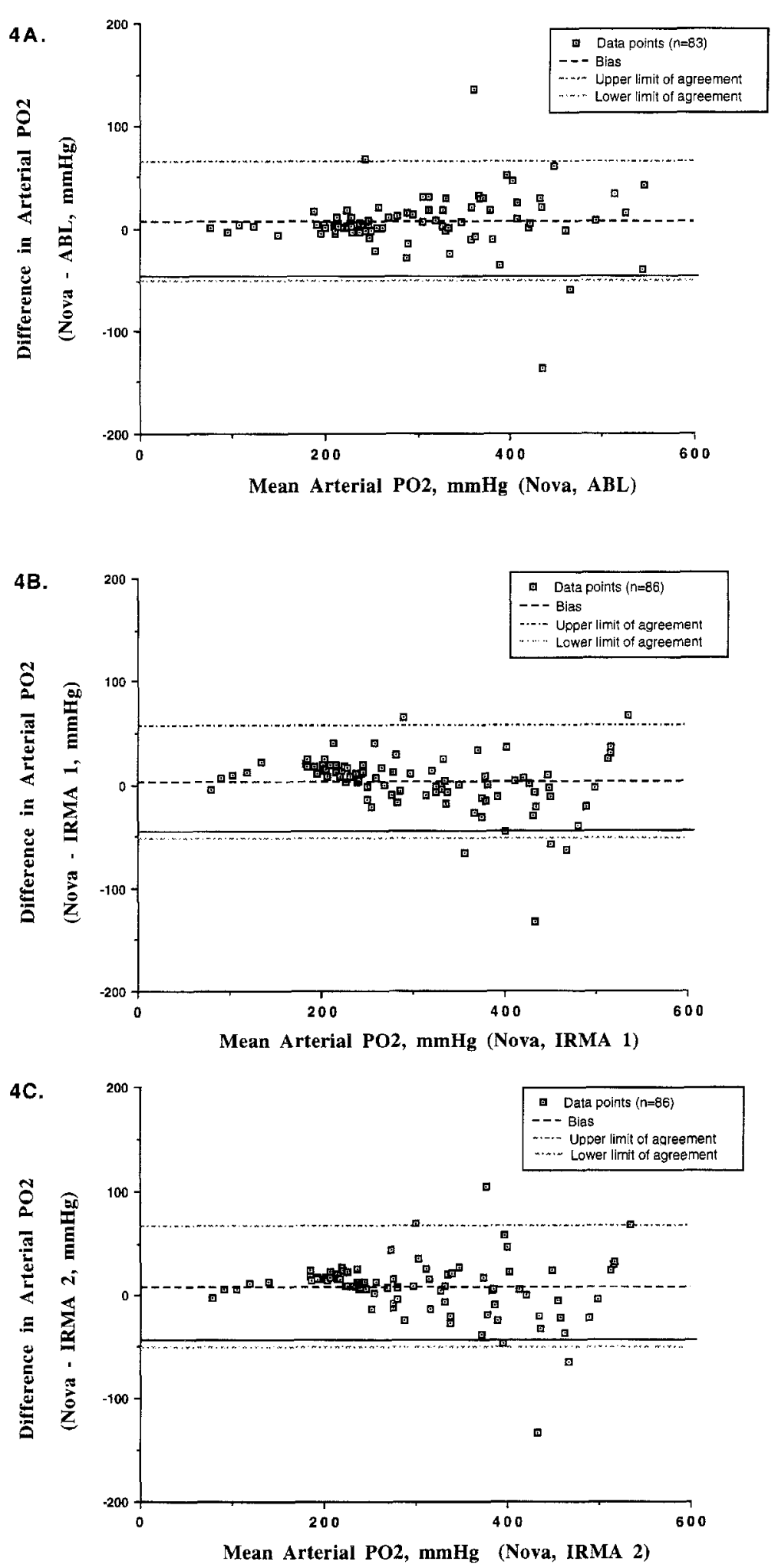

Fig 4. Bias plot of the difference in $\mathrm{PO}_{2}$ measurement between two analyzers and the average of the two measurements, for $\mathrm{PO}_{2}$ values greater than $100 \mathrm{mmHg}$. A. Bias plot of NOVA- and ABL-determined $\mathrm{PO}_{2}$ values; mean difference $=7.4 \pm 29.0 \mathrm{mmHg}$. B. Bias plot of NOVA- and IRMA 1-determined $\mathrm{PO}_{2}$ values; mean difference $=2.1 \pm 27.7 \mathrm{mmHg}$. C. Bias plot of NOVA- and IRMA 2-determined $P \mathrm{O}_{2}$ values; mean difference $=7.6 \pm 29.1 \mathrm{mmHg}$. 
bias, are still excellent. The degree of imprecision, a variation in the $\mathrm{pH}$ value of 0.05 , would rarely be significant clinically.

The limits of agreement comparing the ABL with the NOVA are smaller than those for either IRMA machine compared with the NOVA for $\mathrm{PCO}_{2}$ values, and are the same for $\mathrm{PO}_{2}$ values. The difference in the possible range of agreement for the IRMA machines versus the $A B L$ machine, however, does not appear to be clinically significant $(5.6 \mathrm{mmHg}$ for the $\mathrm{ABL}$ versus 7 to $8 \mathrm{mmHg}$ for the IRMA).

In addition to the irreducible variability in analyzer results, another, often greater, source of error in blood gas analysis occurs during sample handling. The addition of even small amounts of air, too much or too little heparin, or delays in analysis with the sample at room temperature, can introduce substantial error [1-4]. The small size of the IRMA machines permits true "point-ofcare" blood gas analysis, and thus eliminates many of these handling errors. The very small size also may permit use of this blood gas analyzer during field resuscitation and during transport (ambulance and med flight), an option that is not available at present. Finally, the disposable nature of the cartridges reduces the risk of nosocomial infections. An outbreak of Pseudomonas cepacia bacteremia (14 episodes) associated with a contaminated blood gas analyzer has been reported [6]. Benchtop blood gas analyzers aspirate blood into the electrodes, which are rinsed and reused over a period of weeks to months. The IRMA technology permits disposal of the entire blood sample following analysis.

In most settings, the cost of analysis per sample will be lower with this technology than with current benchtop analyzers. The hardware cost of the IRMA analyzer is approximately one-tenth of the cost of an average benchtop analyzer. Although the disposable costs are somewhat higher per sample with the IRMA compared with the benchtop disposables, maintenance costs are expected to be much lower for the IRMA.

There are certain limitations associated with this new technology. Changes in temperature will affect the equilibrium of the bicarbonate and $\mathrm{CO}_{2}$ inside the foil wrappers. Cartridges therefore should not be used until they have spent at least 24 hours in the environment in which they will be used. In current hospital and clinical settings, which have excellent environmental control, temperature does not fluctuate more than a few degrees throughout the entire building. In the field and during transport, however, temperature fluctuations may affect calibration more significantly.

Another limitation of this calibration method is that once the foil wrapper is opened, the $\mathrm{CO}_{2}$ surrounding the electrode will begin to dissipate. Package instructions state that the cartridge should be inserted into the machine and calibration begun within 5 minutes of opening the foil wrapper. While this can be easily accomplished, use of electrodes that have been exposed to room air for long durations will result in calibration errors and subsequent errors in $\mathrm{PCO}_{2}$ results. Finally, methods of ensuring quality control need to be reevaluated for this new technology. Standard quality control for benchtop analyzers involves analysis of known control solutions on a daily or shift basis. This permits recognition and replacement of an electrode that fails to calibrate. Because each electrode (and cartridge) is disposable, testing known solutions will test the calibration and accuracy of only the electrodes in that cartridge. The next cartridge may or may not calibrate to the same accuracy as the cartridge used to analyze the known sample. It may be more valuable to test each lot group, or to test representative samples of a box of cartridges that has been moved to a new environment. The accuracy and precision of the IRMA system demonstrated in this study indicate that calibration is very consistent from cartridge to cartridge, and lot to lot.

In conclusion, the IRMA blood gas analyzer offers point-of-care blood gas analysis with an accuracy and precision that is similar to that of current benchtop analyzers.

\section{REFERENCES}

1. Hamilton RD, Crockett RJ, Alpers JH. Arterial blood gas analysis: Potential errors due to the addition of heparin. Anaesth Intensive Care 1978; 6: 251-255.

2. Biswas CK, Ramos JM, Agroyannis B, Kerr DN. Blood gas analysis: Effect of air bubbles in syringe and delay in estimation. Br Med J 1982; 284 (6320): 923-927.

3. Ishikawa S, Fornier A, Borst C, Segal MS. The effects of air bubbles and time delay on blood gas analysis. Ann Allergy 1974; 33 (2): 72-77.

4. McKane MH, Southorn PA, Santrach PJ, Burritt MF, Plevak DJ. Sending blood gas specimens through pressurized transport tube systems exaggerates the error in oxygen tension measurements created by the presence of air bubbles. Anesth Analg 1995; 81: 179-182.

5. Bland JM, Altman DG. Statistical methods for assessing agreement between two methods of clinical measurement. Lancet 1986; 1 (8476): 307-310.

6. Cartwright K, Tumer H. Safety aspects of outstationed laboratory equipment [see comments]. J Hosp Infect 1992; 20 (4): $225-231$. 